\title{
A new deal for Advances in Oceanography and Limnology (AIOL Journal)
}

\author{
Antonio Pusceddu, ${ }^{1}$ Nico Salmaso ${ }^{2}$ \\ ${ }^{1}$ Dipartimento di Scienze della Vita e dell'Ambiente, Università degli Studi di Cagliari, 09126 Cagliari, Italy; ${ }^{2}$ Dipartimento \\ Agroecosistemi Sostenibili e Biorisorse, Fondazione E. Mach, San Michele all'Adige, Trento, Italy \\ Corresponding author: apusceddu@unica.it ; nico.salmaso@fmach.it
}

With this first double issue of 2015, Advances In Oceanography and Limnology (AIOL Journal) is facing an important regime shift. Published in house until 2007 by the Italian Association of Oceanography and Limnology (AIOL, www.aiol.info) as the Proceedings of the AIOL National Congress, it has been transformed starting from 2011 in a regular scientific journal with the aim of offering a new publication outlet for oceanographers and limnologists. After five volumes (ten issues) published under the editorial responsibility of the former AIOL president Roberto Danovaro between 2011 and 2014, the journal, still sponsored by AIOL, has now passed to Pagepress (www.pagepress.org).

In September 2015, the Presidency Council of the AIOL, corroborated by the vote of the AIOL Members Assembly held in Verbania (Italy), has passed to us the editorial responsibility of the Journal. We have enthusiastically accepted this challenge and we would like here to briefly explain how we intend to pave the way for a new deal of the AIOL journal.

The AIOL Journal was funded as an interdisciplinary Journal, and we want to uphold its wide scope, which embraces both fundamental and applied Oceanography and Limnology, with focus on both single and multiple disciplines. In the modern scientific vision, the adoption of a multidisciplinary approach is essential for understanding the mechanisms of ecosystem functioning and their alteration caused by natural and anthropogenic influences. Such a task requires a diversified Editorial Board, with Associate Editors specialized in different aquatic scientific disciplines, and yet strongly motivated to put together the different pieces that represent the core of the interdisciplinary approach. At present, the AIOL Journal relies on twin Editors in Chief, while a new, compact and agile group of associate editors will be added in the near future. The correct identification of referees is essential for an accurate evaluation of the submitted contributions. We are strongly aware that the selfless and invaluable scientific work of qualified referees are essential for the final quality and impact of the published papers and for the reputation of the AIOL Journal.

With the 2015 issue, the AIOL Journal is now published as a new Open Access, peer-reviewed journal. In the intricate world of publishers, we admit we cannot now compete with highly reputed journal with a longer tradition of publi- cation. We also know that this world is increasingly being populated by a plethora of open access journals from any part of the globe, which increases a lot the competition for attracting esteemed authors as well as receiving high quality papers. So, why the need of another open access journal? The response is astonishingly simple: our aim is to provide a new open-access, free of charge floor for the large community of world oceanographers and freshwater scientists, with an eye on the Mediterranean community. This ambitious aim is possible by the free dedication and support of the Italian Association of Oceanography and Limnology. Wide space is given to regular articles, review, short notes and opinion papers. Proceedings that focus on topics that are timely and of interest to a significant number of aquatic scientists will be equally evaluated for their inclusion in specific issues. The publishing house is guaranteeing a fast and high quality editorial processing of the submitted papers. With this last issue, about 4 months were required from the date of submission and the online publication of papers.

Given its present infancy stage, the AIOL Journal is not yet fully indexed. The AIOL Presidency Council in charge, of which we are honoured to be part of, fostered the publication of the 2015 issue under Pagepress in order to save the publishing effort paid during the first four years of the journal's life and ensure indexing agencies to follow up the journal. This will give Advances in Oceanography and Limnology an opportunity to be monitored and, in a hopefully near future, to be ultimately ranked.

We are conscious that making the AIOL Journal attractive for highly reputed authors will be the major part of the challenge. We will put a special effort to select high quality papers through a rigorous peer reviewing process, also profiting of the future Board of international Associate Editors. We will also put a special effort for mining thematic reviews from esteemed oceanographers and limnologists all over the world, providing a comprehensive state of the art overview and, at the same time, indicating future directions and perspectives in a given field. The ultimate undisguised ambition is thus to give the AIOL Journal an international position in the wide panorama of the already available scientific literature with "water-oriented" aims and scope.

Antonio Pusceddu Nico Salmaso Editors, Advances in Oceanography and Limnology 